\title{
Piodermite profunda por Staphylococcus intermedius em eqüino
}

\author{
Deep pyoderma by Staphylococcus intermedius in equine
}

\begin{abstract}
Fábio Cordeiro Oliveira Santos ${ }^{\mathrm{I}}$ Maria Verônica de SouzaII Dominguita Lühers GraçaIII Agueda Vargas $^{\mathrm{IV}}$ José do Carmo Lopes Moreira ${ }^{\mathrm{V}}$ Bruna Mota Zandim $^{\mathrm{V}}$
\end{abstract} \begin{abstract}
Neste trabalho descreve-se um caso de piodermite,
com tempo de evolução de um mês, de um eqüino de oito anos RESUMO de idade, sem raça definida, com áreas alopécicas, crostas na pálpebra superior, nos membros torácicos e pélvicos, na região do prepúcio e, principalmente, na região do pescoço e escápula. O prurido era discreto. O exame histopatológico revelou dermatite piogranulomatosa perivascular e perianexial associada à hiperplasia epidérmica, além de orto e paraceratose e crostas. O epitélio folicular exibiu focos de espongiose e exocitose de neutrófilos, predominando aspectos de inflamação crônica. A cultura bacteriana identificou o Staphylococcus intermedius a partir das suas características morfo-tintoriais e bioquímicas, com resultados positivos aos testes de catalase, coagulase, glicose e produção ácida aeróbica a partir do manitol. O eqüino foi tratado diariamente com dimetilsulfóxido, gentamicina e dexametasona por via tópica. Mesmo que algumas das lesões apresentaram rápida regressão (sete dias), as localizadas na região do pescoço e escápula demoraram 13 meses para a completa cicatrização.
\end{abstract}

Palavras-chave: cavalo, alopecia, crostas, foliculite estafilocócica.

\section{ABSTRACT}

A case of one month of evolution, of an 8-year-old equine of undefined breed, presenting alopecic areas, crusts on the upper eyelid, forelimbs, hindlimbs, preputial region and mainly, on the neck and scapula is reported. Pruritus was discrete. The histological analysis revealed pyogranulomatous dermatitis round blood vessels and adnexa, associated with epidermal hyperplasia, as well as orthokeratosis, parakeratosis and crusts. The follicular epithelium exhibited foci of spongiosis and exocytosis of neutrophils, with predominant chronic inflammation changes. Bacterial culture identified Staphylococcus intermedius, based on morphology, staining and biochemical tests positive for catalase, coagulase, glucose and aerobic acid production from mannitol. The equine was treated with dimethylsulfoxide, gentamicine and dexamethasone topically on a daily basis. Although some lesions presented rapid regression (7 days), it took 13 months for the complete repair of those lesions of the neck and scapula.

Key words: horse, alopecia, crusts, staphylococcal folliculitis.

Em eqüinos, a pele corresponde entre 20 e $24 \%$ do peso corporal e possui inúmeras funções. Bactérias do gênero Staphylococcus são cocos grampositivos encontrados como comensais da pele, sendo muitas vezes considerados responsáveis por infecções de pele que podem atingir o tecido subcutâneo e a musculatura. Este gênero pode ocasionar várias piodermites, entre elas a foliculite (EVANS \& WHITE, 2002).

'Programa de Pós-graduação em Clínica e Cirurgia Veterinárias, Departamento de Veterinária (DVT), Universidade Federal de Viçosa (UFV), Viçosa, MG, Brasil.

"Setor de Clínica, DVT, UFV, campus universitário, s/n, 36570-000, Viçosa, MG, Brasil. E-mail: msouza@ufv.br. Autor para correspondência.

"'Laboratório de Patologia Veterinária, Departamento de Patologia, Universidade Federal de Santa Maria (UFSM), Santa Maria, RS, Brasil.

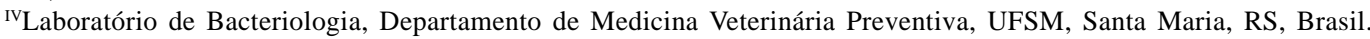

${ }^{\vee}$ Departamento de Veterinária, UFV, Viçosa, MG, Brasil. 
O pioderma é uma foliculite bacteriana que, nos eqüinos, é causada por $\boldsymbol{S}$. aureus, $\boldsymbol{S}$. intermedius, S. hyicus e, menos comumente, por Streptococcus sp. (SCOTT, 1988), C. pseudotuberculosis, R. equi e pelo Bacillus sp. (SCOTT \& MANNING, 1980). A foliculite ocasionada por espécies de Staphylococcus grampositivos apresenta uma distribuição cosmopolita. Não existe predisposição por idade, sexo ou raça, mas eqüinos que são submetidos a manejo higiênicosanitário inadequado (deficiência na higiene do ambiente, controle não apropriado de endo e ectoparasitas) e má nutrição parecem ser mais susceptíveis a desenvolverem a afecção (OUTERBRIDGE \& IHRKE, 2003).

O Staphylococcus intermedius foi descrito por Hajek, em 1976, como uma espécie coagulasepositivo, sendo isolada das vias aéreas superiores de pombos, cachorros, visons e eqüinos (BES et al., 2002). Este agente ocasiona uma dermatopatia relativamente freqüente no eqüino, sendo sua patogênese semelhante à de outras espécies. Quando a barreira protetora natural da pele está comprometida, as bactérias invadem os folículos pilosos e se multiplicam, induzindo inflamação, destruição do folículo piloso e queda do pêlo. Na medida em que a infecção se espalha, as lesões aumentam de tamanho (MORIELLO et al., 2000). Se a inflamação resultar em degeneração e ruptura da parede folicular com contaminação da derme e hipoderme, a lesão passa a ser considerada como furunculose (OUTERBRIDGE \& IHRKE, 2003).

Clinicamente a foliculite bacteriana se caracteriza pela presença de pápulas, úlceras, exsudação serosa, purulenta ou sanguinolenta, formação de crostas, áreas de alopecia e fácil retirada dos pêlos (EVANS \& WHITE, 2002). As regiões mais comumente afetadas são a cervical e a distal dos membros, além da região dorsolombar (local onde a sela é colocada). O quadro é doloroso, mas o prurido não é um achado comum e, quando presente, deve-se considerar a possibilidade de associação à reação de hipersensibilidade. A presença de nódulos sugere que já existe furunculose. No entanto, essas lesões são mais raras, mas podem resultar em um tecido cicatricial com leucoderma e leucotricia (MORIELLO et al., 2000).

O diagnóstico da infecção por Staphylococus sp. é baseado no histórico (época do ano - particularmente na primavera e verão, quando a umidade é mais elevada, os animais perdem o pêlo e aumenta a quantidade de insetos - e manejo inadequado na propriedade), exame físicodermatológico, citologia do exsudato, cultura bacteriana e biópsia de pele para histopatologia (EVANS \& WHITE, 2002; OUTERBRIDGE \& IHRKE, 2003). Esta última técnica é particularmente importante nos casos em que a terapia utilizada não resulta na resolução do quadro (OUTERBRIDGE \& IHRKE, 2003). A histopatologia se caracteriza por graus variados de foliculite, pústulas intra-epidérmicas e inflamação perivascular. Os neutrófilos constituem a célula primária (MORIELLO et al., 2000), mas eosinófilos podem ser encontrados. Adicionalmente, os ceratinócitos freqüentemente exibem edema intracelular, sendo a para e a ortoceratoses comuns nas crostas. O diagnóstico diferencial deve ser realizado com infecções causadas por fungos, outras bactérias piodérmicas, parasitas ou por doença auto-imune, como o pênfigo foliáceo (SCOTT, 1988).

O tratamento deve incluir a remoção e o controle dos fatores predisponentes. Alguns casos são autolimitantes e são resolvidos após algumas semanas de tratamento (OUTERBRIDGE \& IHRKE, 2003). As lesões discretas podem responder ao tratamento com iodo-povidine tópico ou xampu à base de clorexidine, iodofor ou peróxido de benzoíla (EVANS \& WHITE, 2002). Entretanto, casos graves ou crônicos podem necessitar de antibióticos sistêmicos. Em geral, os estafilococos são resistentes à penicilina e a tetraciclinas, sendo a terapia de escolha a sulfa potencializada na dose de $30 \mathrm{mg} \mathrm{kg}^{-1}$, a cada 12 horas, durante três a quatro semanas. É importante que o tratamento seja mantido entre sete e 10 dias após o desaparecimento dos sinais clínicos (OUTERBRIDGE \& IHRKE, 2003).

Portanto, neste trabalho é descrita a ocorrência de piodermite profunda ocasionada por Staphylococcus intermedius em um eqüino macho, mestiço, castrado, de oito anos de idade. $\mathrm{O}$ animal foi atendido no Hospital Veterinário do Departamento de Veterinária da Universidade Federal de Viçosa, com histórico de dermatopatia com um mês de duração. A enfermidade teve início no verão e caracterizava-se por prurido, alopecia, exsudação purulenta e crostas. O animal havia sido medicado pelo proprietário com penicilina benzatina por via intramuscular, na dose de $22.000 \mathrm{UI} \mathrm{kg}^{-1}$ a cada 48 horas (três aplicações) e álcool iodado tópico durante 10 dias consecutivos sem resposta. Segundo o proprietário, o animal era mantido em baia anexada a um piquete, sendo alimentado com capim nativo e milho. Água era deixada à vontade e não havia suplementação com sal mineral. A freqüência de limpeza da baia não era diária e a última vermifugação teria sido há quase um ano.

O exame físico-dermatológico revelou a presença de áreas de alopecia e crostas na região da pálpebra superior do olho esquerdo, na face medial dos membros torácicos (desde o terço médio do úmero 
até a região do carpo), na face caudomedial dos membros pélvicos, na região prepucial e caudal do pescoço até a escápula. Ao redor das áreas de alopecia, os pêlos eram facilmente removíveis, deixando uma região ulcerada e com discreta exsudação purulenta. Observou-se também prurido, de intensidade discreta. Apesar de o quadro apresentado, o apetite era normal, sem alteração nas variáveis temperatura corporal, freqüência cardíaca, freqüência respiratória, tempo de enchimento capilar e grau de hidratação. Os linfonodos regionais encontravam-se normais e não houve comprometimento do sistema locomotor.

Após avaliação física, foi realizada a coleta de material para pesquisa de ectoparasitos (raspado cutâneo), micológico direto (tricografia), exame direto do esfregaço corado pelo Gram (para dermatofilose), biópsia de pele e cultura bacteriológica já amplamente descritos na literatura (CONCEIÇÃO et al., 2004). Para a cultura bacteriológica, foi utilizada a metodologia citada por QUINN et al. (1994); as crostas foram semeadas em placas de Petri contendo Agar Sangue Ovino 5\% e Agar MacConkey e incubadas a $37^{\circ} \mathrm{C}$ durante 48 horas em aerobiose. Para a identificação dos microrganismos, foi observada a característica das colônias nos meios de cultivo e a presença de hemólise. Foram realizadas a coloração de Gram e provas bioquímicas segundo HOLT et al. (1994): catalase, coagulase, utilização de glicose semi-sólida e manitol semi-sólido. Além disso, o teste de Voges-Prouskauer foi utilizado para a diferenciação de cepas coagulase positiva. Para a determinação da susceptibilidade aos antimicrobianos, foi utilizado o método de difusão de disco em Agar Mueller Hinton, de acordo com BAUER et al. (1966).

No hospital veterinário o animal foi mantido em baia, recebeu capim elefante (Pennisetum purpureum) picado e $3 \mathrm{~kg}$ de ração granulada dividida em duas porções e sal mineral e água ad libitum. Diariamente ele era solto em um pequeno piquete para que pudesse se movimentar.

Nas amostras de pêlos e no raspado cutâneo, não houve evidências de estruturas fúngicas ou ectoparasitas. O esfregaço corado pelo Gram demonstrou a presença de cocos gram-positivos. Os cortes histológicos de pele, corados pelos métodos de hematoxilina-eosina (HE) e ácido periódico de Schiff (PAS), revelaram dermatite piogranulomatosa perivascular e perianexial de natureza severa, multifocal e coalescente (Figura 1a), associada à hiperplasia epidérmica, à ortoceratose compacta, à paraceratose $\mathrm{e}$ a crostas. Um dos fragmentos apresentou ulceração com tecido de granulação subjacente (Figura 1b). O epitélio folicular exibia focos de espongiose e exocitose de neutrófilos (foliculite mural). Predominavam aspectos de inflamação crônica, mas microabscessos e infiltrado de neutrófilos foram observados de forma difusa, em torno de vasos e envolvendo o epitélio infundibular e folicular do pêlo. Os granulomas estavam bem constituídos (células gigantes, macrófagos epitelióides e leucócitos) (Figura 1c), provavelmente relacionados com a destruição da parede do folículo piloso (tricogranuloma); extravasamento de detritos celulares; material sebáceo; ceratina e colônias de bactérias na derme; proliferação conjuntiva e neovascularização. Não foram visualizados dermatófitos, ácaros e dermatófilos na camada de ceratina da epiderme dentro dos folículos ou distribuídos na derme. A cultura revelou colônias, com 1 a 2mm de diâmetro, hemolíticas de coloração branco acinzentadas, compostas por cocos gram-positivos. $\mathrm{O}$ microorganismo foi identificado como Staphylococcus intermedius com base nas suas características morfotintoriais e bioquímicas, com resultados positivos aos testes de catalase, coagulase, glicose (fermentação) e produção ácida aeróbica a partir do manitol. Já no teste de Voges-Proskauer (produção de acetoína), o resultado foi negativo, o que permitiu a diferenciação com o $S$. aureus.

No teste de sensibilidade aos antimicrobianos, o agente mostrou-se sensível à cefoperazona, cloranfenicol, eritromicina, gentamicina, neomicina, oxacilina, sendo intermediário à ampicilina e resistente à nitrofurantoína e à polimixina B. A resistência do agente à polimixina $\mathrm{B}$ não era esperada, já que, segundo QUINN et al. (1994), espera-se este resultado somente ao $\boldsymbol{S}$. aureus. Entretanto, a troca de material genético entre microorganismos pode ocasionar esta resistência ao antibiótico, conforme mencionado por SHERLEY et al. (2004).

Devido às similaridades das seqüências dos genes do rRNA e da dificuldade de diferenciação fenotípica entre $\boldsymbol{S}$. intermedius, $\boldsymbol{S}$. delphini e $\boldsymbol{S}$. pseudintermedius, SASAKI et al. (2007) reclassificaram fenotipicamente linhagens identificadas como $\boldsymbol{S}$. intermedius de várias origens, usando análises moleculares filogenéticas. As linhagens foram reclassificadas em quatro grandes grupos: 1) $\boldsymbol{S}$. intermedius, 2) S. pseudintermedius, 3) S. delphini grupo A, e 4) S. delphini - grupo B, sendo este último, segundo os autores, uma nova espécie. Como a identificação do agente causal do presente estudo ocorreu antes da publicação do referido artigo e os métodos de identificação utilizados na época não incluíram decodificação genética, é possível que a linhagem descrita como $\boldsymbol{S}$. intermedius fosse, na verdade, um representante de qualquer um dos grupos relatados por esses autores. 

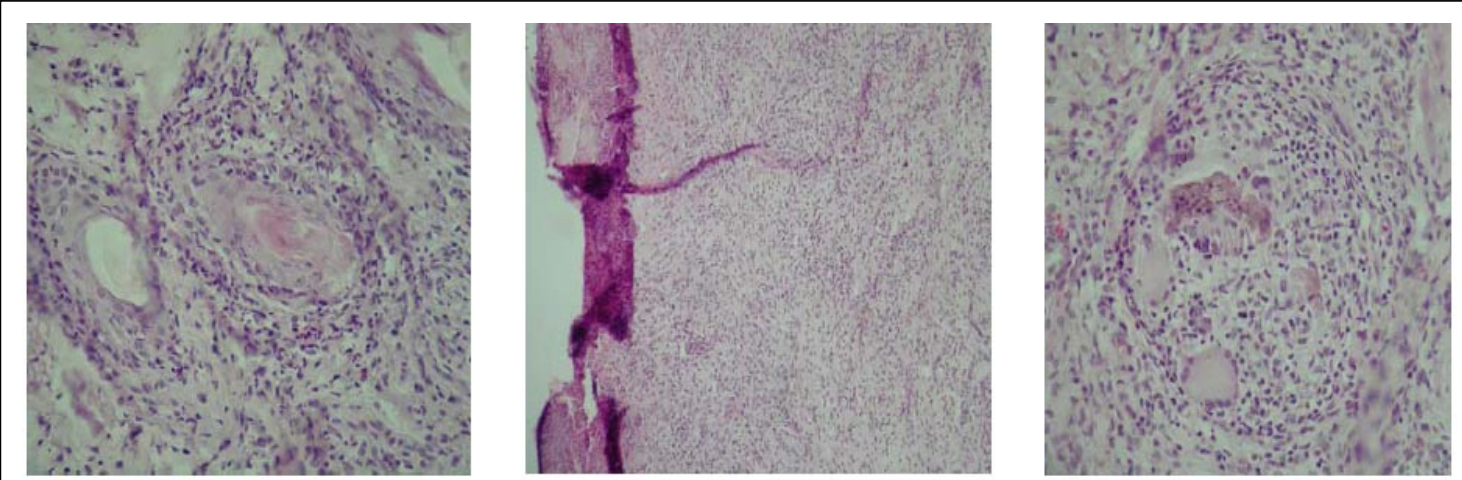

a
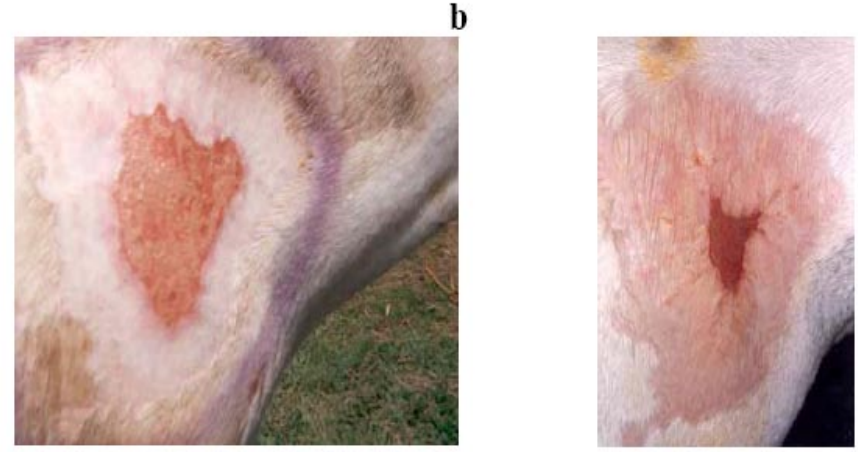

c

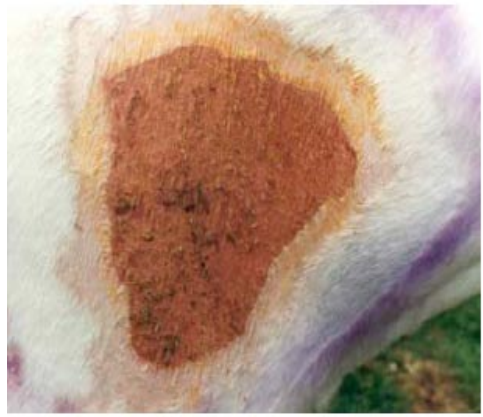

b

d

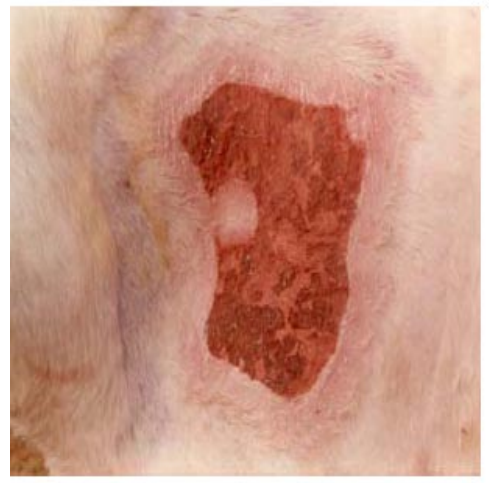

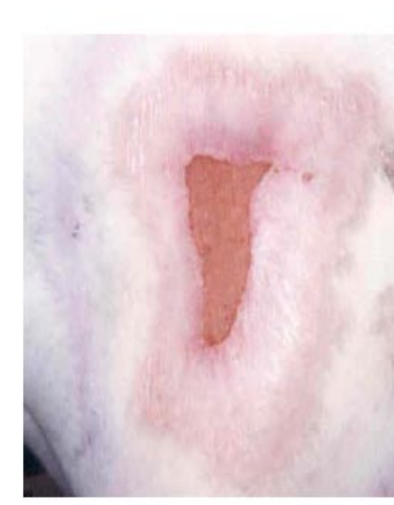

e

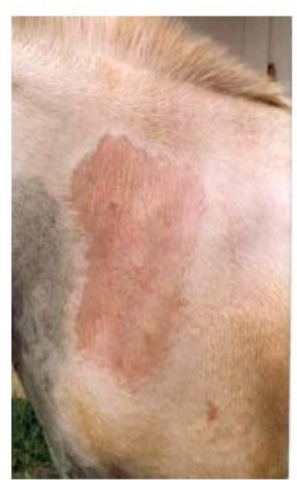

f

g

h

Figura 1 - Avaliação histopatológica (a-c) e evolução clínica do caso (d-i). Observa-se dermatite piogranulomatosa perivascular e perianexial (HE, 400x) (a). Fragmento com ulceração e tecido de granulação adjacente (HE, 100x) (b). Presença de granuloma, constituído por células gigantes e macrófagos epitelióides (HE, 400x) (c). Processo de cicatrização da lesão situada no pescoço e escápula. Lado direito: lesão aos dois meses (d), sete meses (e) e 12 meses (f) depois de iniciado o tratamento local. Lado esquerdo: lesão aos três meses (g) e oito meses (h) de iniciado o tratamento. Pele cicatrizada 13 meses após (i) iniciada a terapia tópica.

Após a identificação do agente, devido às condições financeiras do proprietário, não foi possível optar por uma terapia sistêmica, sendo realizado tratamento tópico. Inicialmente as crostas foram retiradas com líquido de Dakin na diluição de 0,005\%. Em seguida, os locais afetados foram pincelados com solução com 100mL de dimetilsulfóxido (DMSO) a $99,78 \%$, 4000mg de gentamicina e 20mg de dexametasona. As lesões da pálpebra, prepúcio e membros cicatrizaram após sete dias. Já as lesões situadas na região do pescoço e escápula apresentaram uma regressão muito lenta (Figura 1d, e, f), demorando 13 meses para desaparecerem completamente (Figura 1g, h, i), o que pode ser decorrente da profundidade da lesão e da mobilidade da área afetada. Adicionalmente, em alguns locais, o pêlo não voltou a aparecer devido

Ciência Rural, v.38, n.9, dez, 2008. 
à gravidade da lesão e à alopecia cicatricial (ACKERMAN et al., 2005) nas lesões profundas (SCOTT, 1988).

Os quadros clínico e histopatológico observados são compatíveis com piodermite profunda por estafilococos, caracterizada pela presença de folicute, infundibulite e furunculose. Entretanto, como os sinais são comuns à dermatofilose, à celulite estafilocócica, a dermatites generalizadas e a exsudativas por outros agentes (SCOTT, 1988; MORIELLO et al., 2000), é fundamental a realização de exames complementares. O tratamento sistêmico, quando não há resposta à terapia tópica (SCHWARZ \& NOBLE, 1999), poderia ter reduzido o tempo de cicatrização das lesões, mas aumentaria o custo do tratamento. Segundo SCOTT et al. (2000), os fatores mais influentes na eficácia do antibiótico sistêmico nas dermatopatias são a sensibilidade da bactéria à droga utilizada e a distribuição do medicamento em quantidades adequadas na pele. Sabe-se que apenas $4 \%$ do volume de sangue proveniente do débito cardíaco alcançam a pele, comparado a 33\% nos músculos. A eficácia do tratamento tópico com DMSO depende da concentração utilizada (geralmente de 5 a $50 \%$ ) e do microrganismo envolvido (SCOTT, 1988). Como o estrato córneo é a principal barreira de permeabilidade para a adequada penetração dos medicamentos tópicos, a utilização deste fármaco foi fundamental no tratamento deste caso clínico por suas propriedades antiinflamatória, analgésica, antimicrobiana e antifúngica, entre outras.

\section{REFERÊNCIAS}

ACKERMAN, A.B. et al. Histologic diagnosis of inflammatory skin diseases. In: Basic patterns and analysis of them. 5.ed. New York: Ardor Scribendi, 2005. Cap.5, p.181373 .

BAUER, A.W. et al. Antibiotic susceptibility testing by a standardized single disk method. American Journal of Clinical Pathology, Chicago, v.45, p.493-496, 1966.

BES. M. et al. Population diversity of Staphylococcus intermedius isolates from various host species: typing by 16AS23S intergenic ribosomal DNA spacer polymorphism analysis. Journal of Clinical Microbiology, Washington, v.40, n.6, p.2275-2277, 2002.
CONCEIÇÃO, L.G. et al. Biópsia e histopatologia da pele: um valioso recurso diagnóstico na dermatologia - revisão - parte 1. Clínica Veterinária, São Paulo, ano IX, n.51, p.36-44, 2004.

EVANS, A.G.; WHITE, S.D. Bacterial diseases. In: SMITH, B.P. Large animal internal medicine. 3.ed. St. Louis: Mosby, 2002. v.2, cap.38, p.1207-1208.

HOLT, J.G. et al. Bergey's manual of determinative bacteriology. 9.ed. Baltimore: Williams \& Wilkins, 1994. 787p.

INOKUMA, H. et al. Equine pyoderma associated with malnutrition and unhygienic conditions due to neglect in a herd. Journal of Veterinary Medical Science, Tokyo, v.65, n.4, p.527-529, 2003.

MORIELLO, K.A. et al. Enfermidades da pele. In: REED, S.M.; BAYLY, W.M.. Medicina interna eqüina. Rio de Janeiro: Guanabara Koogan, 2000. Cap.10, p.442-480.

OUTERBRIDGE, C.A.; IHRKE, P.J. Folliculitis: Staphylococcal pyoderma, dermatophilosis, and dermatophytosis. In: ROBINSON, N.E.. Current therapy in equine medicine. 5.ed. Philadelphia: Saunders, 2003. Cap.48, p.197-198.

QUINN, P.J. et al. Clinical veterinary microbiology. London: Wolfe, 1994. 648p.

SASAKI, T. et al. Reclassification of phenotypically identified Staphylococcus intermedius strains. Journal of Clinical Microbiology, Washington, v.45, n.9, p.2770-2778, 2007.

SCHWARZ, S.; NOBLE, W.C. Aspects of bacterial resistance to antimicrobials used in veterinary dermatologic practice. Veterinary Dermatology, Edinburgh, v.10, n.3, p.163-176, 1999.

SCOTT, D.W.; MANNING, T.O. Equine folliculitis and furunculosis. Clinical Techniques in Equine Practice, New York, v.2, p.11-32, 1980.

SCOTT, D.W. Immunologic diseases. In: Large animal dermatology. Philadelphia: Saunders, 1988. Cap.10, p.306-311.

SCOTT, D.W. et al. Muller and Kirk's small animal dermatology. 6.ed. Philadelphia: Saunders, 2000. Cap.4, p.274-335.

SHERLEY, M. et al. Evolution of multi-resistence plasmids in Australian clinical isolates of Escherichia coli. Microbiology, Reading, v.150, p.1539-1546, 2004. 